\title{
Corrosion Reliability of Lead-free Solder Systems Used in Electronics
}

\author{
$\underline{\text { Feng } \mathrm{Li}^{1)}}$, Vadimas Verdingovas ${ }^{1)}$, Bálint Medgyes ${ }^{2)}$, and Rajan Ambat ${ }^{1)}$ \\ ${ }^{1)}$ Department of Mechanical Engineering, \\ Technical University of Denmark, 2800 Kgs. Lyngby, Denmark \\ s150901@ student.dtu.dk \\ ${ }^{2)}$ Department of Electronics Technology, \\ Budapest University of Technology and Economics, 1111 Budapest, Hungary
}

\begin{abstract}
Corrosion reliability of five $\mathrm{Sn}-\mathrm{Ag}-\mathrm{Cu}$ (SAC) based lead-free solder alloys under humid and corrosive conditions has been investigated to understand the microstructure effects on corrosion performance. Electrochemical experiments such as potentiodynamic and potentiostatic tests were conducted in $3.5 \mathrm{wt} \%$ sodium chloride electrolyte at room temperature. Microstructure of the solder alloys and corrosion surface morphology was evaluated using light optical microscope (LOM) scanning electron microscopy (SEM), energy dispersive spectroscopy (EDS) and X-ray diffraction (XRD). During the potentiostatic tests, the cathodically active Bi phase in InnoLot alloy introduced pitting in the Sn phase nearby, whereas $A g_{3} S n$ phase prompted pitting on the adjacent to $\beta$-Sn phase in SAC 305, SACX Plus 0307, SACX 0807 and SACX Plus 0807 solder alloys.
\end{abstract}

\section{INTRODUCTION}

$\mathrm{Sn}-\mathrm{Pb}$ solder alloys have been widely used in electrical and electronic equipments, however it is being phased out due to the toxicity of lead. Therefore, from July of 2006, the regulation of inhibiting the usage of hazardous substances in the electrical and electronic equipment (RoHS) directive restricted the utility of lead in new electronic equipment [1]. Katsuaki [2] and Yun [3] reported that the SAC alloy family is the prominent lead-free alternative based on the result of DICTRA simulation and its eutectic microstructure. A number of composition based on SAC has been tried for various properties regarding to melting temperature, thermal/electrical conductivity, expansion coefficient and compatibility to applied flux system etc. [3]. Bismuth, copper and silver has been reported to form eutectic intermetallic compounds (IMCs) with tin at approximate $139{ }^{\circ} \mathrm{C}, 227^{\circ} \mathrm{C}$ and $221^{\circ} \mathrm{C}$ respectively [3]. Ho et al. [4] reported nickel and copper presented $\left(\mathrm{Cu}_{1-\mathrm{x}} \mathrm{Ni}_{\mathrm{x}}\right)_{6} \mathrm{Sn}_{5}$ phase when the concentration of $\mathrm{Cu}$ is 0.6-3.0 wt\%. While in a recent study [5], it has been reported that Innolot has the best anti-fatigue performance due to the attribution of $\mathrm{Bi}$ and $\mathrm{Sb}$ to the formation of $\mathrm{Ag}_{3} \mathrm{Sn} \mathrm{IMC}$. A number of investigations in the literature deals with microstructure and mechanical properties of SAC solder alloys [3], [59], however only few studies have been reported on corrosion reliability aspects and the role of solder alloys microstructure. Most of the reported investigations were focused on potentiodynamic polarization test [10-12]. About $100 \mathrm{mV}$ scatter in the equilibrium potential for SAC solder has been reported by Li et al. [10], which is attributed to the uneven distribution of IMCs. In the current study, the solder alloys based on SAC with additions of $\mathrm{Bi}, \mathrm{Sb}$, and $\mathrm{Ni}$ were investigated. The focus is placed on the influence of IMCs and their contribution to the corrosion reliability of solder alloys.

\section{Materials AND EXPERIMENTAL MethodS}

\subsection{Material Preparation}

Five solder pastes were supplied by commercial companies; Table 1 shows the elemental composition of the alloys used in the current study. The pastes have been melted respectively and formed ingots in Pyrex glass tube 
Table 1. Composition of five solder alloys used for investigation.

\begin{tabular}{|c|c|c|c|c|c|c|}
\hline & Sn [wt\%] & $\mathrm{Ag}[\mathrm{wt} \%]$ & $\mathrm{Cu}[\mathrm{wt} \%]$ & $\mathrm{Bi}[\mathrm{wt} \%]$ & $\mathrm{Sb}[\mathrm{wt} \%]$ & $\mathrm{Ni}[\mathrm{wt} \%]$ \\
\hline No. 1 & 96,5 & 3,0 & 0,5 & & & \\
\hline No. 2 & 98,95 & 0,3 & 0,7 & & & 0,05 \\
\hline No. 3 & 98,4 & 0,8 & 0,7 & 0,1 & & \\
\hline No. 4. & 98,45 & 0,8 & 0,7 & & & 0,05 \\
\hline No. 5 & 90,95 & 3,8 & 0,7 & 3,0 & 1,4 & 0,15 \\
\hline
\end{tabular}

with protection of vacuum chamber and argon gas, to avoid void formation and surface oxidation. A copper wire was connected by soldering on one side of alloy ingot, in order to create electrical contact needed during electrochemical testing conducted afterwards with the samples. The ingot samples with the wire attached were cold mounted using epoxy (Epofix Resin, EpoDye, Struers, Denmark). The surface of the ingot was polished using 320, 500, 1000, 4000 grits, then $3 \mu \mathrm{m}$ and $1 \mu \mathrm{m}$ diamond suspension supplied by Struers, Denmark. The surface finishing was done using $50 \mathrm{~nm}$ neutral alumina suspension (Akasel, Denmark). An insulation tape has been used to mask the working area $\left(113,10 \mathrm{~mm}^{2}\right)$ of the polished surface.

\subsection{Microstructural and Phase Analysis}

In order to identify the microstructure and illustrate the corrosion influence of IMCs in solder alloys, LOM (GX41, Olympus, Japan) and SEM (Inspect S, FEI, USA, with an EDS detector, Oxford Instrument, UK) have been used. The IMCs phase analysis of five solder alloys has been carried out using XRD with a Mo anode (D8 Advance, Bruker, USA). The LOM images, backscattering images (BSI, voltage 20V, spot size 3.5) and EDS mapping were taken before and after corrosion tests.

\subsection{Corrosion Tests}

For corrosion tests, the potentostatic pitting technique has been introduced using "Biologic VSP" single
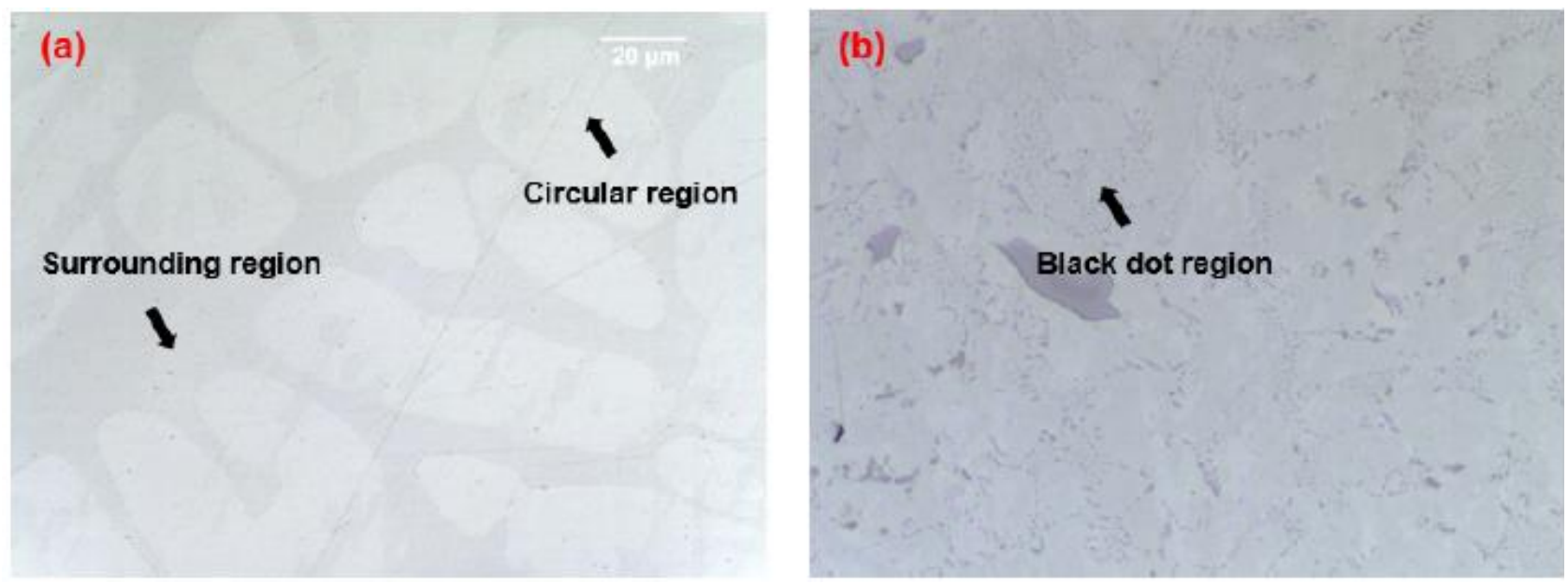

Fig. 1. LOM micrographs of five novel solder alloy, (a) No. 1 alloy, (b) No. 2 alloy.

potentiostat (Bio-Logic Instrument, France). Platinized titanium counter electrode and $\mathrm{Ag} / \mathrm{AgCl}$ saturated $\mathrm{KCl}$ reference electrode have been used during corrosion test. The surface of the specimen immersed in 3.5 wt $\%$ sodium chloride aqueous solution. For slight pitting generation of solder alloy surface, the potential has been set as $50 \mathrm{mV}$ for $3 \mathrm{~min}$ after $5 \mathrm{~min}$ stabilization of open circuit potential $\left(\mathrm{E}_{\mathrm{oc}}\right)$. To observe the final morphology of corrosion surface, the potential has been set as $500 \mathrm{mV}$ for $10 \mathrm{~min}$ after $5 \mathrm{~min}$ stabilization of $\mathrm{E}_{\mathrm{oc}}$. 


\section{ReSUlts AND DiscuSSION}

\subsection{Microstructure and Phase Analysis Before Corrosion test}

Two phases have been observed in the No. 1 alloy as circular phase and surroundings (Fig. 1. (a)), whereas three phases have been seen in No. 2-5 as black dot region, dark grey phase and bright grey phase, shown in Fig. 1. The quantity of black dot region in No. 4 alloy was significantly higher than in No. 2 alloy. This could be due to the higher concentration of silver in No. 4 alloy as compared to No. 2 alloy. It is possible to infer that the
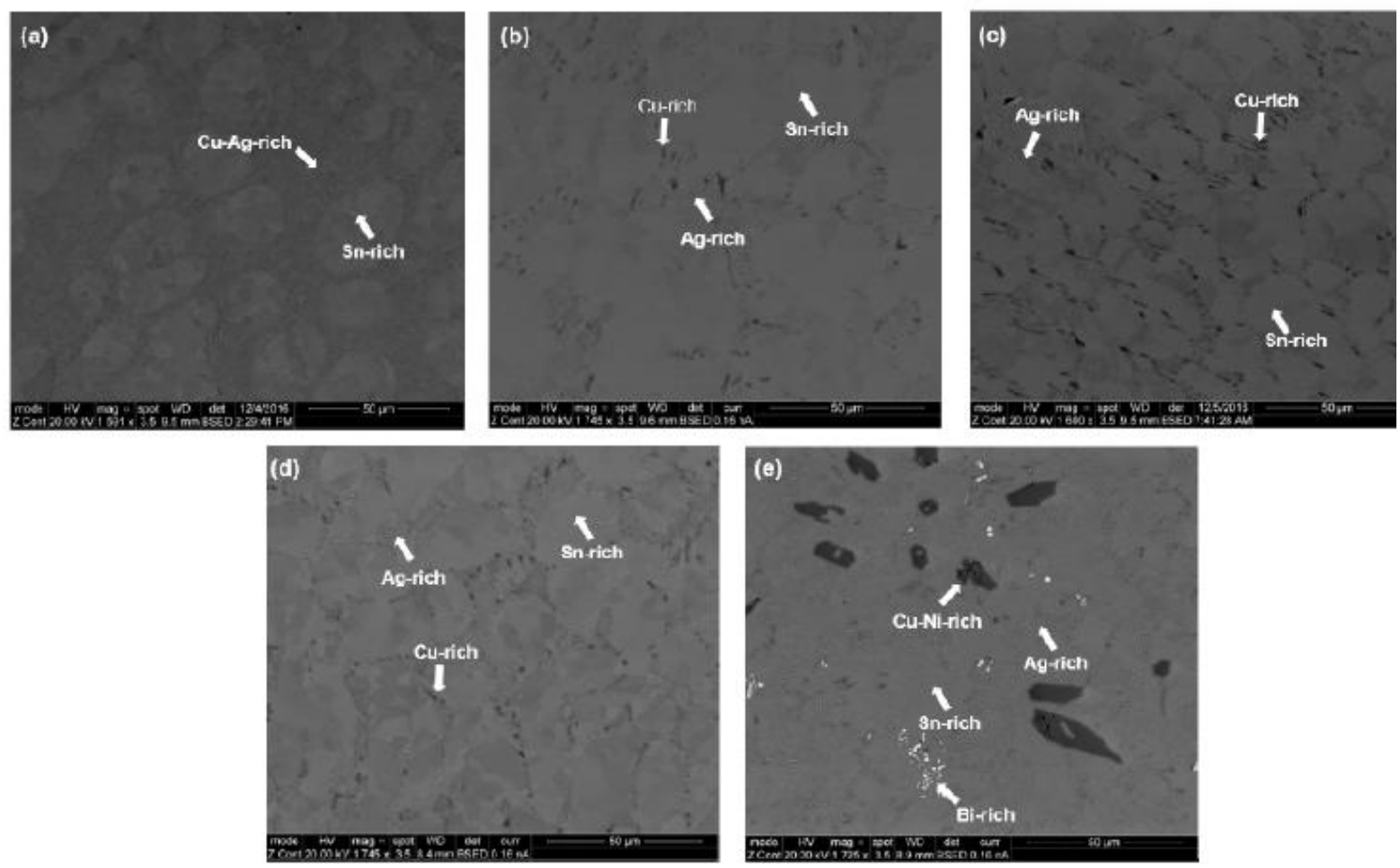

Fig. 2. BSI micrographs of five solder alloy and EDS results, (a) No. 1 alloy, (b) No. 2 alloy, (c) No. 3 alloy, (d) No 4. alloy, (e) No. 5 alloy.

black dot phase is Ag-rich phase. The quantity of black dot like phase in No. 2 alloy is the highest among these five solder alloys. Addition of $\mathrm{Bi}$ and $\mathrm{Sb}$ has been reported to increase the formation of $\mathrm{Ag}_{3} \mathrm{Sn}$ phase [5]. Two phases have been found from BSI micrographs and EDS mapping result in Fig. 2 (a) and Fig. 3 (a) as Sn phase and $\mathrm{Ag}-\mathrm{Cu}$-rich phase, which have been reported as $\beta$-Sn phase and Ag-Cu-rich eutectic phase [13]. In Fig 2 (b) (c) and (d), three phases have been observed in No. 2-4 as Sn phase, Cu-rich phase and Ag-rich phase. For No. 5 alloy, as Tao et al. reported [14], Sn-Sb-rich phase has been observed as the main compound from the EDS mapping result, as shown in Fig. 2 (e), which is different compared to that of the rest four alloys. Also, Cu-Nirich phase has been found as the dark grey region in Fig. 2 (e) due to the solid solution formed by $\mathrm{Cu}$ and $\mathrm{Ni}$, which has been discussed by Lin et al. [15]. Bi-rich phase has been found as the white region.

Fig. 3 illustrates the phase combination of five solder alloys. In No. 1 alloy, two phases have been observed in Fig. 2 (a), however three phases have been found in XRD result as $\beta-S n, A g_{3} S n$ and $\mathrm{Cu}_{6} \mathrm{Sn}_{5}$ phases, which has been reported as $\beta-\mathrm{Sn}$ and $\mathrm{Cu}_{6} \mathrm{Sn}_{5}+\mathrm{Ag}_{3} \mathrm{Sn}$ eutectic phases [16]. XRD signal of $\beta$-Sn, $\mathrm{Cu}_{6} \mathrm{Sn}_{5}$ and $\mathrm{Ag}_{3} \mathrm{Sn}$ has been found in the rest of four solder alloys as well. But in fact, the Cu-rich phase should be $(\mathrm{Cu}, \mathrm{Ni})_{6} \mathrm{Sn}_{5}$ in No. 2 , 4, 5 alloys, Sb was homogeneously distributed in No. 5 alloy and Sn-rich phase should be (Sn $\mathrm{Sb}$ ) phase. Additionally, Bi phase has been found in No. 5 alloy as a pure phase rather than eutectic phase. 


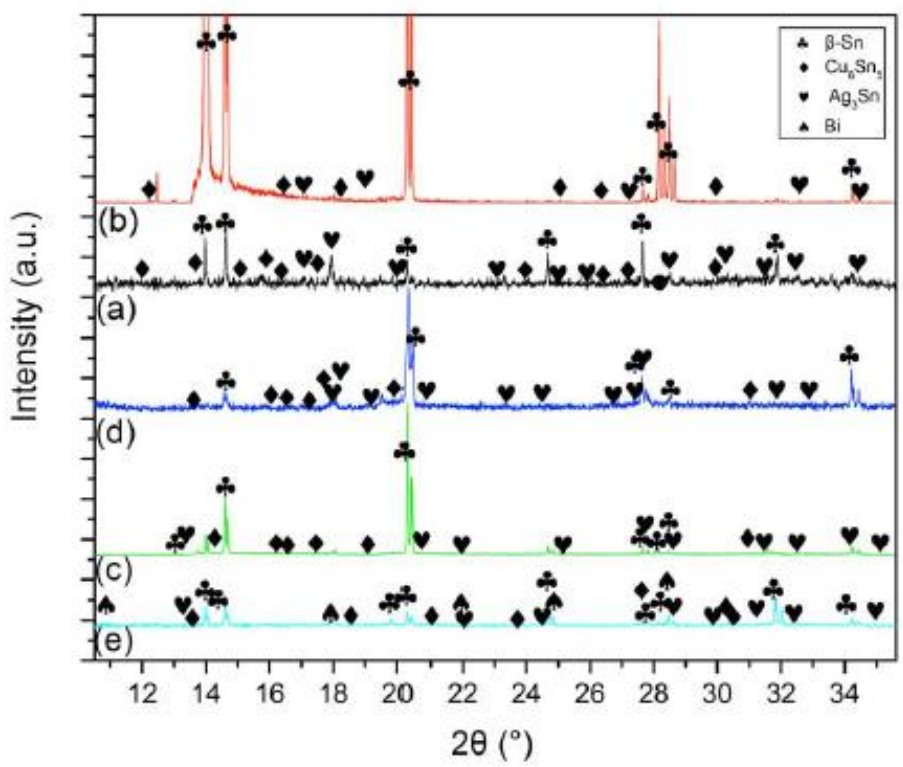

Fig. 3. XRD phase analysis results of five solder alloys: (a) No. 1 alloy, (b) No. 2 alloy, (c) No. 3 alloy, (d) No 4. alloy, (e) No. 5 alloy.
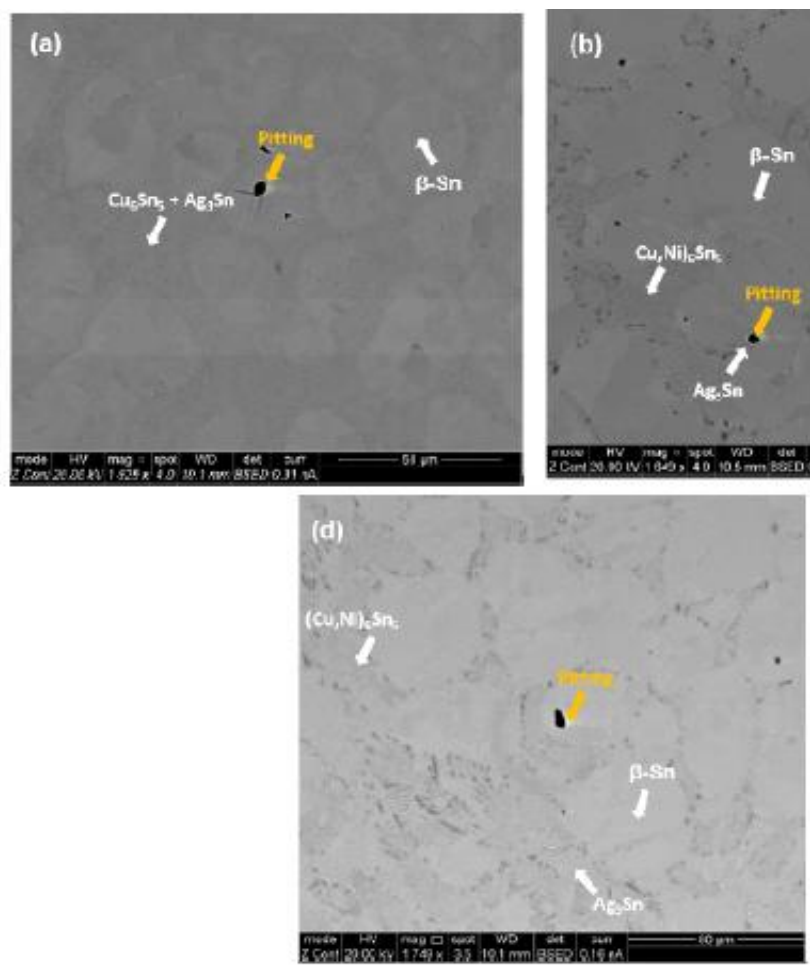
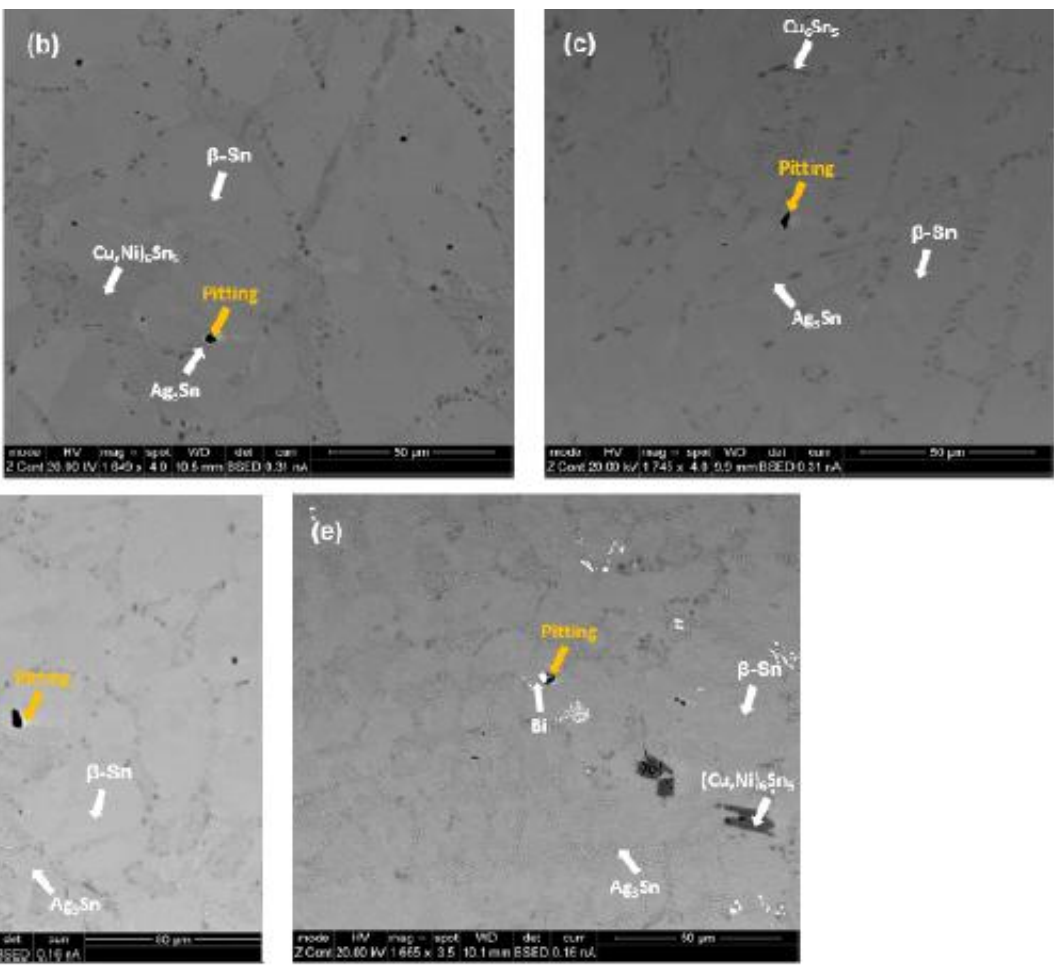

Fig. 4. BSI micrographs of five solder alloys after applying $50 \mathrm{mV}$ over Eoc for $3 \mathrm{~min}$ : (a) No. 1 alloy, (b) No. 2 alloy, (c) No. 3 alloy, (d) No. 4 alloy, (e) No. 5 alloy. 
After applying $50 \mathrm{mV}$ for $3 \mathrm{~min}$, the pitting formation occurred at preferred phase for all the five alloys, shown as bright grey phase in Fig. 4. The BSI micrographs indicates that the preferred pitting formation phase is $\beta$-Sn phase; however, the cathodically active phases in five solder alloys are not the same. Fig. 4. (a) illustrates No. 1 alloy the cathodically active phase is $\mathrm{Ag}_{3} \mathrm{Sn}+\mathrm{Cu}_{6} \mathrm{Sn}$ eutectic phase, whereas Fig. 4. (b) (c) and (d) possibly infer that $\mathrm{Ag}_{3} \mathrm{Sn}$ IMCs acted as cathodically active phase in No. 2-4 alloys and attributed to the pitting generation to the $\beta$-Sn on the adjacent of the $\mathrm{Ag}_{3} \mathrm{Sn}$ phase. Fig. 4. (e) elucidates Bi phase cathodically active pitting formation on the $\beta$-Sn phase nearby in No. 5 alloy. In order to clarify the dark $\mathrm{Cu}_{6} \mathrm{Sn}_{5}$ phase and the dark pitting void, supplementary EDS mapping tests after corrosion tests has been introduced. EDS mapping result indicates that the dark region is pitting void rather than $\mathrm{Cu}_{6} \mathrm{Sn}_{5}$ phase. Corrosion product generation has been observed in No. 1-4 after applying $500 \mathrm{mV}$ over $\mathrm{E}_{\mathrm{oc}}$ for $10 \mathrm{~min}$. Fig. 5. illustrates the morphology of No.1 alloy surface after

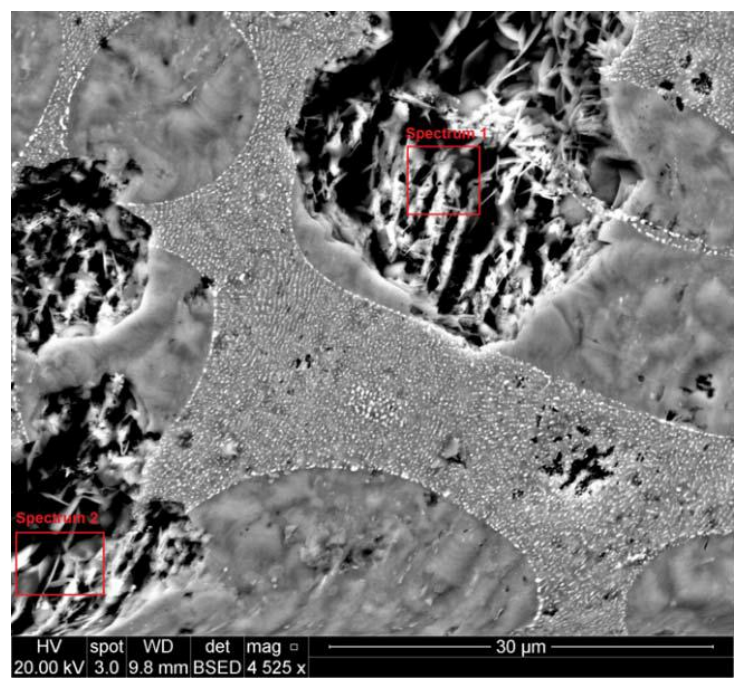

Fig. 5. BSI micrograph of No. 1 alloys after applying $500 \mathrm{mV}$ over Eoc for $10 \mathrm{~min}$.

heavy potentiostatic corrosion. $\mathrm{Ag} 3 \mathrm{Sn}$ IMCs on the surface has been confirmed that it maintained the same surface morphology as what it looks like before corrosion tests. The Ag3Sn phase acted as cathodically active phase and triggered the formation of corrosion product from $\beta$-Sn phase, after a while, the reaction rate of corrosion was obstructed by the buildup of corrosion product. However, the surface of No. 5 alloy kept dissolving and the surface had been destroyed. Since the corrosion current of Sn-Sb alloy was not different much compared to the pure Sn, reported by Alberto et al [17], the Sb content thusly does not affect the corrosion behavior of $\mathrm{Sn}$ phase. The corrosion started with the influence of cathodically active Bi phase. High content of Ag signal has been collected using EDS after applying $500 \mathrm{mV}$ over Eoc for $10 \mathrm{~min}$, which inferred more severe corrosion has been introduced by the high content of activated Ag3Sn IMCs.

\section{Conclusion}

Potentiostatic pitting technique has been employed in order to avoid the disadvantage of equilibrium potential scattering during polarization tests, and it can provide the possibility to clarify the influence of IMCs to corrosion reliability by controlling applied voltage, the time of applying voltage as well as the concentration of electrolyte.

- In No. 1-4 solder alloys, pitting formation of $\beta$-Sn phase is attribute to cathodically activated Ag3Sn phase. The title does not match the rules of uppercase characters,

- In No. 5 solder alloy, the pitting generation of $\beta$-Sn phase started as the influence of cathodically activated pure $\mathrm{Bi}$ phase in low potential, then with the increasing potential activated $\mathrm{Ag}_{3} \mathrm{Sn}$ can increasing the corrosion rate of $\beta$-Sn phase, 
- No. 5 solder alloy has the worst corrosion reliability behavior compared to the rest of four solder alloys. The corrosion product of No. 5 alloy kept dissolving in sodium chloride aqueous solution, whereas the corrosion product of the rest of four solder alloys formed on the surface and inhibited the corrosion reaction.

\section{ACKNOWLEDGEMENT}

Bálint Medgyes would like to thank the support for the National Research, Development and Innovation Office - NKFIH, PD 120898.

\section{REFERENCES}

[1] [1]" Waste Electrical \& Electronic Equipment (WEEE)", European Commision, 09 ${ }^{\text {th }}$ Jun. 2016, http://ec.europa.eu/environment/waste/weee/index en.htm, Accessed $07^{\text {th }}$ Feb. 2017.

[2] K. Suganuma, "Advance in Lead-free Electronics Soldering", Current Opinion in Solid State and Materials Science, Vol. 5, Issue 1, August 2001, pp. 55-64.

[3] Y. Zhang, "Tin and Tin alloys for Lead-free Solder ", Mordern Electroplating, Fifth Edition, John Wiley \& Sons Inc, 2010, pp.139-204.

[4] C. E. Ho, R. Y. Tsai, Y. L. Lin, C. R. Kao, "Effect of Cu Concentration on the Reactions Between Sn-Ag-Cu Solders and Ni ", Journal of Electronic Materials, Vol. 31, Issue 6, February 2002, pp. 584-590.

[5] M. N. Colins, E. Dalton, J. Punch, "Microstructural Influences on Thermomechanical Fatigue Behaviour of Third Generation High Ag Content Pb-free Solder Alloys", Journal of Alloy and Compounds, Vol. 688, Part B, July 2016, pp 164-170.

[6] K. S. Kim, S.H. Huh, K. Suganuma, "Effects of Cooling Speed on Microstructure and Tensile Properties of Sn-AgCu Alloys", Materials Science and Engineering: A, Vol. 333, Issue 1-2, September 2001, pp. 106-114.

[7] K. S. Kim, S.H. Huh, K. Suganuma, "Effects of Fourth Alloying on Microstructures and Tensile Properties of SnAg-Cu Alloy and Joints With Cu", Microelectronic Reliability, Vol. 43, Issue 2, December 2002, pp. 259-267.

[8] Z. Yang, W. Zhou, P. wu, "Effects of Ni-coated Carbon nanotubes Addition on the Microscture and Mechanical Properties of Sn-Ag-Cu Solder Alloys", Material Science and Engineering: A, Vol. 590, September 2013, pp. 295300.

[9] G. Chen, F. Wu, C. Liu, V. V. Silberschmidt, Y. C. Chan, "Microstructure and Properties of New Sn-Ag-Cu Leadfree Solder Reinforcement with Ni-coated Graphene Nanosheets", Journal of Alloy and Compounds, Vol. 656, September 2015, pp. 500-509.

[10] D. Li, P.P Conway, C. Liu, "Corrosion Characterization of Tin-lead and Lead Free sikders in $3.5 \mathrm{wt} \% \mathrm{NaCl}$ Solution", Corrosion Science, Vol. 50, Issue 4, February 2007, pp. 995-1004.

[11] F. Rosalbino, E. Angelini, G. Zanicchi, R, Marazza, "Corrosion Behavior Assessment of Lead-free Sn-Ag-M (M = In, Bi, Cu) Solder Alloys", Material Chemistry and Physics, Vol. 109, Issue 2-3, December 2007, pp. 386-391.

[12] M. Fayeka, M. A. Fazal, A. S. M. A.Hasseb, "Effects of Aluminum on the Electrochemical corrosion behavior of Sn$3 \mathrm{Ag}-0.5 \mathrm{Cu}$ Solder Alloy in 3.5wt\% NaCl Solution", J mater Sci: Mater Electron, Vol. 27, November 2013, pp. 12193-12200.

[13] A.A El-daly, W. M. Desoky, T. A. Elmosalami, M. G. El-Shaarawy, A.M. Abdraboh, "Microstructural Modifications and Properties of SiC Nanoparticles-reinforced Sn-3.0Ag-0.5Cu Solder Alloy ", Material \& Design, Vol. 65, January 2015, pp. 1196-1204.

[14] Q. B. Tao, L. Benabou, K. L. Tan, J. M. Morelle, F. B. Ouezdou, "Creep Behaviour of Innolot Solder Alloy Using Small Lap- Shear Specimens", December 2015, 17 $7^{\text {th }}$ Electronic Packaging Technology Conference.

[15] C. H. Lin, S. W. Chen, C. H. Wang, "Phase Equilibria and Solidification Properties of Sn-Cu-Ni Alloys", Journal of Eletronic Materials, Vol.31, Issue 9, June 2002, pp. 907-915.

[16] Z. G. Chen, Y. W. Shi, Z. D. Xia, Y. F. Yan, "Study of Microstructure of a Novel Lead-Free Solder Alloy SnAgCuRE and Its Soldered Joints", Journal of Electronic Materials, Vol. 31, Issue 10, July 2002, pp. 1122-1128.

[17] A. Torres, L. Hernández, O. Domínguez, "Effect of Antimony Additions on Corrosion and Mechanical Properties of Sn-Bi Eutectic Lead-Free Solder Alloy", Materials Sciences and Applications, Vol. 3, April 2012, pp. 355-362. 